\title{
Willkommen in der Zukunft
}

Künstliche Intelligenz (KI) ist ein Thema, das Menschen schon seit Langem fasziniert. Von HAL in Kubricks/Clarkes „2001“ über zahllose intelligente Roboter etwa in „iRobot“ oder Blade Runner. Immer steht die Frage im Zentrum: Was ist eigentlich Intelligenz? Können Maschinen intelligent sein? Die Entwicklung auf diesem Gebiet in den vergangenen Jahren ist beeindruckend. Selbst das Go-Spielen haben Computer inzwischen gemeistert und besiegen hochkarätigste menschliche Gegner. Das eigentlich Spannende sind aber nicht so sehr solche Vorzeigeprojekte. Die Verknüpfung von Technologien wie Deep Learing, Big Data \& Co. ist gerade dabei, unser aller Leben ein-

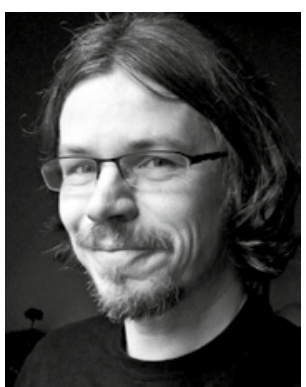

Peter Pagel

Chefredakteur schneidend zu verändern. So erreicht beispielsweise die Interaktion zwischen Mensch und Maschine ein völlig neues Niveau.

Ein charakteristisches Merkmal der aktuellen Entwicklung ist, dass Maschinen an unterschiedlichsten Stellen automatisiert Daten erzeugen beziehungsweise sammeln. Verknüpft man diese miteinander, entstehen ganz neue Möglichkeiten und auch Risiken. Ist Datenschutz ein Auslaufmodell? Sollten wir uns vielleicht eher darauf konzentrieren, mit dem Verschwinden der Privatsphäre umzugehen, als einen Kampf gegen Windmühlen zu führen, wie es Michal Kosinski, Assistant Professor an der Stanford University in diesem Jahr auf einer Veranstaltung zur Digitalisierung in Berlin vorschlug?

Neben solch ethischen Fragen ist es für Unternehmen besonders wichtig, aus der Vielzahl an neuen Technologien diejenigen herauszufiltern, die mehr sind als kurzfristige Hypes oder Modeerscheinungen. Eines ist klar: Wir befinden uns in vielerlei Hinsicht in einer Zeit, die wir bislang nur aus der Science-Fiction kannten, aus Utopien und aus Dystopien.

Es liegt an jedem Einzelnen, der in diesem Bereich arbeitet, in welche Richtung das Pendel zukünftig ausschlagen wird.

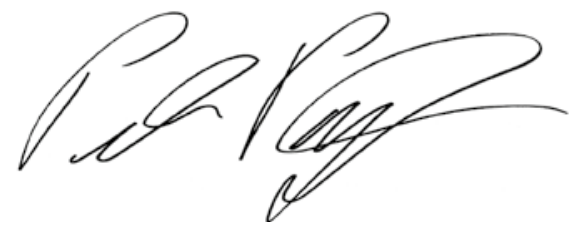

Peter Pagel

P.S.: Eine Einführung zu den Artikeln unseres Schwerpunkts lesen Sie ab Seite 8. 